\title{
GOSTOVANJE IGRALSKE DRUŽBE CARLA MEYERJA V MARIBORSKEM GLEDALIŠČU
}

\author{
Manica špendal (Maribor)
}

V sezonah $1840 / 41$ in $1841 / 42$ je gostovala $\mathrm{v}$ mariborskem gledališču igralska družba Carla Meyerja. Predstave gostujočih gledaliških družb, domačega Diletantskega društva pa tudi koncertni nastopi in druge kulturne prireditve so bile v obdobju od 1806 do $1852 \mathrm{v}$ kaj neprimernem prostoru - v opuščeni cerkvi sv. Duha, ki je stala na mestu današnje pošte I na Slomškovem trgu $10{ }^{1}$

Iz virov je razvidno, da Carl Meyer, ki je imel enterprizo v mariborskem gledališču v omenjenih dveh sezonah, ni identičen s slovitim komikom in gledališkim direktorjem Carlom Meyerjem (roj.1.1750), ustanoviteljem dunajskega Theatra in der Josefstadt (1.1788), ker je le-ta 13. V. 1930 umrl v 80. letu starosti. ${ }^{2}$ Skoraj gotovo pa je Carl Meyer, ki je gostoval v letih 1840/41 in 1841/42 v Mariboru, isti impresarij, ki je imel dvakrat enterprizo v zagrebškem gledališču, v sezonah 1830-1834 in 1338/39, kar potrjuje primerjava nekaterih njegovih uprizoritev $\mathrm{v}$ mariborskem oziroma $\mathrm{v}$ zagrebškem gledališču kot npr. del F. Raimunda in J. Nestroya. ${ }^{3}$

1 Že konec 18. stol. so po nalogu cesarja Jožefa II. nekatere opuščene mariborske cerkve sekularizirali - med njimi tudi cerkev sv. Duha v Cerkveni ulici (Kirchgasse) pri tedanji bolnišnici, t. j. na prostoru današnje pošte I na Slomškovem trgu $10 . \mathrm{V}$ njej je delovalo mariborsko gledališče od 1806 do 1852 . Vladimir Kralj opisuje v svojem prispevku "Preteklost mariborskega gledališča podobo nekdanjega mariborskega gledališkega hrama takole: "Poslopje je bilo mračno in že $v$ razpadanju. Gledališki prostor se je bočil nad nekdanjimi grobnicami, med katerimi so domovale podgane. Mesta je bilo v njem za $300 \mathrm{oseb}$, parter in lesena galerija, ki so jo nosili leseni stebri, sta štela 104 sedeže. Oder je bil tako nizek, da so igralci s čelom zadevali ob njegov oboj in jim pri viteških igrah ni bilo videti vihrajočih perjanic«. Gl. Kralj V., Preteklost mariborskega gledališča, Kronika slovenskih mest IV, 1937, str. 14.

2 Prim. Rommel O., Die Alt Wiener Volkskomödie, Wien 1952, str. 425; Kosch W., Deutsches Theater Lexikon II, Klagenfurt 1960, str. 1394.

3 Prim. Breyer B., Das Deutsche Theater in Zagreb 1780-1840, Zagreb 1937, str. 74 in 82. 
Meyerjeva gledališka družba je bila od dotedanjih najkvalitetnejša tako glede programa kakor tudi glede reprodukcije. Da v Mariboru njegovo ime že pred enterprizo ni bilo ravno neznano, spoznamo iz besed gledališkega poročevalca R. Puffa v Aufmerksamu: "Velik sloves, ki ga uživa sedanji podjetnik tukajšnjega gledališča Carl Meyer kot človek in direktor, bo nedvomno spoznala tudi naša, za umetnost zainteresirana publika. « ${ }^{\prime}$

Jasno je, da se Meyerjeva prizadevanja glede repertoarja v Mariboru niso mogla razvijati v enaki smeri kot v Zagrebu, kjer je uvrstil v sporede tudi pomembnejša operna dela. V Mariboru so mogla biti na programu le odrska dela, ki so ustrezala miselnosti in zahtevam provincialnega občinstva. To so bili razni igrokazi s petjem, veseloigre ipd. V začetku sezone 1840/41 je Meyer med drugim uprizoril Die magische Eilwagenreise durch die Komödienwelt, ${ }^{5}$ quodlibet $\mathrm{v}$ šestih delih J. Nestroya; Das Turnier zu Kronstein, ${ }^{6}$ veliko romantično veseloigro v petih dejanjih F. von Holbeina, in Christina, Königin von Schweden, ${ }^{7}$ lirično tragedijo $\mathrm{v}$ treh dejanjih P. A. Wolffa.

Z začetkom leta 1841 se je stanje v Meyerjevi družbi kvantitativno in kvalitativno še nekoliko zboljšalo $s$ prihodom dveh novih članov Materne in Olefkega. ${ }^{8} \mathrm{~V}$ spored je Meyer med drugim uvrstil tudi

${ }^{4}$ Prim. Der Aufmerksame, 1840, št. 151, str. 4.

${ }^{5}$ Prim. Der Aufmerksame, 1840, št. 156, str. 4. Skladatelj v poročilu ni omenjen. K večini Nestroyevih del je napisal glasbo Adolf Müller sen., vendar pa v nadrobnem seznamu Müllerjevih del. A. Bauerja (Verzeichnis der Theaterkompositionen von Adolf Müller sen.) to delo ni navedeno.

6 Prim. Der Aufmerksame, 1840, št. 156, str. 4. Skladatelj v poročilu ni naveden. F. Hadamowsky označuje Das Turnier zu Kronstein oder Die drey Wahrzeichen kot veliko romantično veseloigro - spektakel $\mathrm{v}$ petih dejanjih F. von Holbeina $\mathrm{z}$ glasbo Andreasa Scutte; prva izvedba je bila 7. VI. $1834 \mathrm{v}$ Theatru in der Leopoldstadt. Andreas Scutta je naveden v delu Die Alt Wiener Volkskomödie O. Rommela le kot eden vidnejših igralcev dunajskega gledališča Theater in der Leopoldstadt v 30. letih prve pol.19. stol. Kot skladatelj ni omenjen v leksikalni literaturi. Pisal je priložnostno tudi glasbo $\mathrm{k}$ odrskim delom kot npr. $\mathrm{k}$ Raimundovi pravljici Moisasur's Zauberflucht. Prim. Hadamowsky F., Das Theater in der Wiener Leopoldstadt 1781-1860, Wien 1934, str. 265; Rommel O. ib., str. 748; Cvetko D., Zgodovina glasbene umetnosti na Slovenskem II, Ljubljana 1959, str. 274.

7 Prim. Der Aufmerksame, 1840, št. 156, str. 4. Christina, Königin von Schweden (Cristina, di Svezia) je omenjena v Stiegerjevem opernem leksikonu kot opera $\mathrm{v}$ treh dejanjih $\mathrm{z}$ imeni manj znanih ital. skladateljev (iz l. 1836), ki pa je ostala nedokončana. V katalogu glasbene zbirke dunajske Narodne knjižnice (Musiksammlung der Nationalbibliothek) pa je omenjena kot Christina di Swezia, tragedia lirica di Felice Romani, posta in musica di S. Thalberg, la rappresentazione nel Teatro di Corte a Porta Carinzia, la primavera 1855. Prim. Stieger F., Opernlexikon, ms., 1934, öNB, S. M. 8960, str. 212; Katalog der Abendländischen Handschriften der ÖNB Wien 1965.

8 Prim. Der Aufmerksame, 1841, št. 8, str. 4. 
dve znani, v tem času na vseh avstrijskih odrih zelo priljubljeni burki in eno romantično igro: 3. januarja 1841 Der Kirchtag in Petersdorf oder Die beyden Nachtwächter, ${ }^{9}$ lokalno burko v dveh dejanjih K. Meisla z glasbo W. Müllerja; 6. januarja 1841 Preciosa oder Das spanische Zigeunermädchen, romantično igro $v$ štirih dejanjih P.A. Wolffa $z$ glasbo C. M. von Webra, in to v korist igralke Amtmannove; ${ }^{10} 28$. januarja 1841 Die falsche Primadonna oder Catalanis Triumfeinzug in Krähwinkel, komično opereto $\mathrm{v}$ dveh dejanjih A. Bäuerla $\mathrm{z}$ glasbo W. Müllerja — v korist igralca Langa. Ob koncu prvega dejanja je orkerster, pomnožen s člani Diletantskega društva; s solistom A. Langom izvedel veliko bravurozno arijo princese iz komične opere Jean de Paris F. Boiëldieuja, quodlibet s spremljavo kitare, arijo Una voce poco fa iz opere Seviljski brivec G. Rossinija ter finale iz opere Sonnanbula V. Bellinija. ${ }^{11}$ Meyer je bil eden prvih impresarijev, ki so v Mariboru kljub težkim materialnim razmeram in celo kljub okusu občinstva vsaj občasno predstavili tudi tehtnejša dela; to dokazuje predvsem uprizoritev Webrove Preciose. Ta se je prav zaradi Webrove glasbe, ki sodi med najpomembnejše stvaritve, kar jih je Weber

${ }_{9}$ Prim. MPA, (Mariborski pokrajinski arhiv), zbirka vabil na prireditve 1790-1949, mapa Mestno gledališče Maribor, vabila in plakati 1798; Der Aufmerksame, 1841, št. 8, str. 4. Der Kirchtag in Petersdorf oder Die beyden Nachtwächter je na lepaku omenjena kot podeželska burka v dveh dejanjih K. Meisla in z glasbo W. Müllerja; prva izvedba je bila 21. VIII. 1819 v Theatru in der Leopoldstadt. Prim. Bauer A., Oper und Operette in Wien, Graz - Köln 1955, str. 57; Rommel O., ib., str. 4.

10 Prim. MPA, zbirka vabil na prireditve 1790-1839, mapa Mestno gledališče Maribor, vabila in plakati 1798; Der Aufmerksame, 1841, št. 8, str. 4.

11 Prim. MPA, zbirka vabila na prireditve 1790-1839, mapa Mestno gledališče Maribor, vabila in plakati 1798. Die falsche Primadonna, prvoten naslov Die falsche Catalani je burka v dveh dejanjih A. Bäuerla in $\mathrm{z}$ glasbo I. Schusterja, ki vsebuje satirično ost proti pretirani slavi in čaščenju tedanje slovite pevke Angelice Catalani. Ker je cenzura prepovedala prvotni naslov burke, so dejanje prestavili v Krähwinkel ter delo imenovali Die falsche Primadonna in Krähwinkel; prva izvedba je bila 18. XII $1818 \mathrm{v}$ Theatru in der Leopoldstadt. Na mariborskem lepaku je delo naslovljeno Die falsche Primadonna oder Catalanis Triumfeinzug in Krähwinkel A. Bäuerla $\mathrm{z}$ označbo komična opereta $\mathrm{v}$ dveh dejanjih, $\mathrm{z}$ glasbo W. Müllerja. Verjetno gre za glasbo, ki jo je Müller napisal k čarobni igri Die Fee in Krähwinkel kot posebnemu delu h glavni burki Die falsche Primadonna, in ki ga F. Hadamowksy označuje kot čarobna igra s petjem v dveh dejanjih, A. Bauer pa celo kot čarobna opera; prva izvedba je bila 27. X. $1826 \mathrm{v}$ Theatru in der Leopoldstadt. V uvodu poudarja avtor teksta A. Bäuerle, da burka nima lokalnega značaja, saj so jo predvajali kot nemško igro že v Leipzigu, Hamburgu, Bratislavi, Münchnu, Frankfurtu in Magdeburgu. K istemu delu je pozneje (1.1850) napisal glasbene točke tudi A. Müller sen. Prim. Rommel O., ib., str. 753; Hadamowsky F., ib., str. 129; Bauer A., Oper und Operette in Wien, str. 321; Bauer A., Verzeichnis der Theaterkompositionen von. A. Müller senior, ms., WSB, J. Nr. 67519. 
ustvaril na področju scenske glasbe $\mathrm{k}$ dramskim delom, ohranila do danes in je bila uprizorjena na vseh večjih evropskih odrih. ${ }^{12}$

$\mathrm{Z}$ omenjenima dvema burkama je Meyer mariborski publiki razmeroma pozno predstavil glasbo Wenzla Müllerja, v času od zadnjega desetletja 18. stol. in $\mathrm{v}$ prvih desetletjih 19. stol. najpopularnejšega predstavnika dunajskega singspiela, katerega dela so zlasti $\mathrm{v}$ prvih desetletjih prejšnjega stoletja prevladovala na odrih avstrijske monarhije. ${ }^{13}$

12 Preciosa ali Das spanische Zigeunermädchen je romantična igra, ki jo je po zgradbi M. Cervantesa La Gitanella napisal P. A. Wolff. Glasbene točke je skomponiral na pobudo grofa K. von Brühla C.M. von Weber (prva izvedba je bila $1.1821 \mathrm{v}$ Berlinu). $\mathrm{K}$ istemu delu je napisalo glasbo več skladateljev: C. Eberwein (1.1811), J.P.C. Schulz (1.1812) in I. von Seyfried (1.1812). Njihovo glasbo pa so kmalu prenehali izvajati, medtem ko se je Webrova scenska glasba $\mathrm{k}$ temu delu zaradi svoje umetniške prepričljivosti ohranila do danes. Zaradi obveznosti, ki jih je imel kot kapelnik v opernih gledališčih v Wroclawu (Breslau), Pragi in Dresdenu ter zaradi dobrih stikov, ki jih je gojil z gledališči v Stuttgartu, Münchnu in Berlinu, je Weber moral napisati kdaj pa kdaj tudi priložnostno glasbo $h$ kakemu odrskemu delu. Od teh je glasba $\mathrm{k}$ Preciosi, kot že omenjeno, najpomembnejša tovrstna stvaritev. Komponirati jo je začel neposredno po operi Der Freischütz, in to maja in junija 1820. Glasba k Preciosi vsebuje 12 točk: koračnice, plese, zbore in pesmi, v katerih je Weber umel izvrstno poustvariti značilen španski ciganski kolorit. V skladu z vsebino in okoljem igre je umel pričarati špansko deželo in življenje ciganov. S to glasbo je Weber kot prvi skladatelj pokazal, še bolj kot v nekaterih prejšnjih delih (glasba k Schillerjevi Turadont, opera Abu Hasan in nekatere manjše instrumentalne skladbe), velik smisel za nacionalno glasbo tujih narodov. Sočasno pa se je naslonil tudi na domačo narodno tvornost, in sicer na značilno nemško romantiko gozda, kot kažejo zborovske točke (št. 6) »Im Wald«, (št. 9) »Die Sonn erwacht«, pa tudi pesem Preciose "Einsam bin ich, nicht alleine « je napisana povsem v nemškem ljudskem duhu. Da se je Weber tudi sam zavedal pomena tega odrskega dela, je razvidno iz pisma, ki ga je 1.1820 pisal grofu Brühlu, v katerem je med drugim dejal: „Das ist ein schweres und bedeutendes Stück Arbeit, über eine halbe Oper". Prim. Bauer A., Oper und Operette in Wien, str. 79; Loewenberg A., Annals of Opera 1597-1940, Cambridge 1943, str. 671; MGG XIV, str. 309 (A. A. Abert); Kroll E., Carl Maria von Weber, Potsdam 1934, str. 114-117.

13 Wenzel (Vaclav) Müller (1767-1835) je deloval skoraj 50 let kot kapelnik in skladatelj $\mathrm{v}$ Theatru in der Leopoldstadt in je tako njegovo ustvarjalno delo tesno povezano $\mathrm{z}$ razvojem te ustanove, saj je napisal glasbo za okrog 250 odrskih del 30 različnim avtorjem, med drugim A. Bäuerlu, K. Meislu, A. Gleichu, L. Huberju, J. Perinetu in K. F. Henslerju, s katerimi je veliko sodeloval. Najboljše prispevke pa je ustvaril ob koncu svojega skladateljskega delovanja $\mathrm{k}$ delom $\mathrm{F}$. Raimunda. Kljub temu, da njegova dela ne sodijo med večje umetniške stvaritve, velja naglasiti njegov delež za razvoj avstrijskega ljudskega gledališča. Poseben razvojni pomen imajo njegovi komični singspieli in parodirane operete, ki pomenijo prehod od singspiela do dunajska operete. Njegovo ime so sicer kmalu pozabili, melodije pa $\mathrm{v}$ narodnih pesmih živijo še danes, npr. "Kommt ein Vogel geflogen«, "So leb denn wohl, du stilles Haus", "Wer nie einen rausch gehabt« idr. Prim MGG IX., str. 568-569 (A. Würz); Krone W., Wenzel Muiller, Wien 1906, str. 19; Keller O., Die Operette in ihrer geschichtlichen Entwicklung, Leipzig - Wien - New York 1926, str.81. 
Carl Meyer je s svojo igralsko družbo predstavil mariborskemu gledališkemu občinstvu tudi dva najslovitejša dunajska ljudska dramatika F. Raimunda in J. Nestroya; uprizoril je dve njuni pomembnejši deli: Nestroyevo burko Der böse Geist Lumpacivagabundus oder Das liedererliche Kleeblatt ${ }^{14}$ (januarja 1841) in Raimundovo pravljico Der Verschwender ${ }^{15}$ (februarja 1841).

14 Prim. Der Aufmerksame, 1841, št. 8, str. 4. Natančen datum uprizoritve ni znan. Poročilo je datirano z 19.1.1841. Der böse Geist Lumpacivagabundus ali Das liederliche Kleeblatt je čarobna komična burka v treh dejanjih J. Nestroya, h kateri je napisal glasbo A. Müller sen.; prva izvedba je bila 11. IV. $1833 \mathrm{v}$ Theatru an der Wien. Johann Nestroy (1801-1862) je po svoji pevski karieri, ko je $\mathrm{z}$ uspehom nastopal kot basist (angažma v dunajski Dvorni operi, gostovanja v Amsterdamu, Hamburgu, Hannovru, Leipzigu, Dresdenu, Gradcu in Brnu), začel 1.1831 svojo drugo kariero kot igralski komik $\mathrm{v}$ Theatru an der Wien, kamor ga je bi poklical tedanji direktor Karl Carl ter ga angažiral kot tretjega komika poleg sebe in Wenzla Scholza. K. Carl je tedanji repertoar sestavljal iz parodij, quodlibetov, romantičnih iger, veseloiger, ljudskih pravljic, čarobnih iger ipd., glavni poudarek pa je dal takrat zelo priljubljenim parodiranim burkam $\mathrm{s}$ petjem. Prav Nestroy je v tistem času še dokaj pomanjkljivi tovrstni literaturi prispeval dela trajnejše vrednosti. Svoj prvi uspeh na tem področju je imel prav z burko Der böse Geist Lumpacivagabundus 1.1833. $\mathrm{Z}$ njim se je pričela tako imenovana "Nestroyeva era", trajala pa je tri desetletja. Lumpacivagabundus je tudi prva Nestroyeva burka, ki je izšla $\mathrm{v}$ tisku (Dunaj l. 1833); v njej se je avtor naslonil na novelo K. Weisflogsa. (Delo pri prvi izvedbi ni uspelo, ampak šele pri tretji uprizoritvi; pozneje so ga prevedli tudi v angleški, francoski, ruski, češki in madžarski jezik). Glasbo k Lumpacivagabundusu je napisal A. Müller sen., ki je v letih 1832-1847 zložil glasbene točke $\mathrm{k}$ več kot polovici Nestroyevih del. Ko je začel s tem delom, je bil že priznan skladatelj ljudske gledališke glasbe. V Lumpacivagabundusu ima glasba še pomembno mesto; tako je tudi $\mathrm{v}$ vseh zgodnejših Nestroyevih čarobnih igrah, parodijah, večdelnih quodlibetih ter burkah do 1.1840. Zato imajo značaj singspiela in vsebujejo arije, zborovske odlomke, duete, tercete, kvartete, melodrame, tu in tam tudi večje ansamble. Zelo pomembni so še quodlibeti, ki so komponirani za solo, ansambel ali zbor. Ti povezujejo znane melodične odlomke iz oper ali singspielov s samostojnimi odlomki skladatelja. V quodlibetih je Nestroy posebno rad vstavljal melodične odlomke iz Mozartove opere Čarobna piščal, $\mathrm{v}$ kateri je nekoč kot basist $\mathrm{v}$ vlogi Sarastra $\mathrm{z}$ velikim uspehom nastopal. Tudi quodlibet $\mathrm{v}$ Lumpacivagabundusu vsebuje arijo Sarastra, pri čemer melodija ni parodirana (»In diesen heil'gen Hallen ... . V V tem delu je tudi zelo učinkovita Müllerjeva glasba, ki je napisana čisto $\mathrm{v}$ ljudskem duhu, tako npr. quodlibet tercet $\mathrm{z}$ zborom. Ta ima poleg opernih odlomkov še dvoje ljudskih napevov in nekaj izvirnih Müllerjevih melodij. Prim. Bauer A., Oper und Operette in Wien, str. 13; Bauer A., Die Musik in den Theaterstücken J. Nestroys, Wien, 1935, str. 101-114; Szmolyan W., Sternenstuden im Theater an der Wien 1801 bis 1830, Theater und Schauspiel, ÖMZ 1962, Sonderband, str. 26; Rommel O., Gesammelte Werke J. Nestroy, Wien 1948, I, str. 575; Wurzbach C., Bingraphisches Lexikon XX, str. 208; Kosch W., ib., I, str. 1619.

15 Prim. Der Aufmerksame, 1841, št. 18, str. 4. Der Verschwender, originalna čarobna pravljica $\mathrm{v}$ treh dejanjih je zadnje in najpomembnejše tovrstno delo Ferdinanda Raimunda; prva izvedba je bila 20. II. 1834 v Theatru in der Josefstadt. Glasbo $k$ Verschwenderju je napisal Konrad (din) Kreutzer (1780-1849), predstavnik lirične romantične opere v prvi polovici 19. stol. Kreutzer je bil tipični eklektik in $\mathrm{v}$ njegovih skladbah 
Če izvzamemo $\mathrm{v}$ začetku sezone izveden manj znan Nestroyev quodlibet Die magische Eilwagenreise durch die Komödienwelt, je to po doslej dosegljivih podatkih $\mathrm{v}$ časopisju oziroma ohranjenih lepakih prvo srečanje $\mathrm{z}$ omenjenima znamenitima dramatikoma. Njuna dela so zaradi svoje izvirnosti in duhovitosti, pri kateri večkrat ne manjka aluzij na sodobne politične in socialne razmere, še danes sveža ter skoraj po 150 letih prav tako kot nekdaj zabavajo avstrijsko gledališko občinstvo.

Sočasno se je publika seznanila tudi z glasbo Adolfa Müllerja sen., ${ }^{16} \mathrm{v}$ tedanjem času izredno priljubljenega skladatelja glasbenih parodij, singspielov, vaudevillov idr., ki so bila dalj časa na programih vseh štirih dunajskih, pa tudi drugih provincialnih avstrijskih gledališč.

Avtor članka Das Stadt-Theater in Marburg (E. H.) ter V. Kralj v svojih prispevkih v mariborskem gledališču trdita, da je J. Nestroy - prav tako kot njegov veliki igralski sodobnik W. Scholz - nekaj časa gostoval tudi $\mathrm{v}$ mariborskem gledališču. ${ }^{17}$ Verjetno sta sklepala, da je bilo to v času, ko je Nestroy v prvem razdobju svoje gledališke

(samospevi, odrska dela) so očitni vplivi Mozarta, Beethovna, Schuberta in Webra. Dasi je napisal 30 glasbeno scenskih del, sta se do danes na sporedih ohranili le dve: opera Das Nachtlager in Granada in glasba $\mathbf{k}$ Raimundovemu Verschwenderju. Pri prvi izvedbi Verschwenderja je v vlogi Valentina $\mathrm{z}$ velikim uspehom nastopil sam F. Raimund. Tudi znamenita pesem o obliču "Da streiten sich die Leut' herum" je zložil Raimund in ne Kreutzer. Prim. Rommel O., Die Grossen Figuren der Alt Wiener Volkskomödie, Wien 1946, str.37; Rommel O., Ferdinand Raimund, Gesammelte Werke, Wien 1962, str. 519; MGG št. VII, str. 1778-1779 (W. Rehm); Gregor J., Schauspielführer, Stuttgart 1953, str. 96-97; Reclams Opernführer Stuttgart 1957, str. 105.

${ }^{16}$ Adolf Müller sen. (1801-1886) je bil eden najpopularnejših in najplodovitejših skladateljev ljudske gledališke glasbe. V času svojega delovanj kot kapelnik in skladatelj $\mathrm{v}$ Theatru an der Wien in Theatru in der Leopoldstadt je zložil glasbo $\mathrm{k}$ nič manj kot 660 odrskim delom (okrog 4418 glasbenih točk.) Med drugim tudi k stvaritvam K. Elmarja, K. Haffnerja, J.F. Berga in A. Langerja. Posebno se je proslavil s scensko glasbo, ki jo je napisal $\mathrm{k}$ Nestroyevim delom - podobno kot W. Müller $\mathrm{k}$ Raimundovim - in pozneje $\mathrm{k}$ Anzengruberjevim kmečkim burkam. Njegova velika popularnost se kaže tudi v tem, da so njegove opere, operete, singspiele, glasbene parodije, melodrame, vaudevilli in burke dolgo prevladovale na sporedih štirih dunajskih gledališč in je pogosto celo naneslo, $\mathrm{da}$ so isti večer kar $\mathrm{v}$ dveh ali več gledališčih izvajali njegovo glasbo. Nič manj priljubljene niso bile njegove glasbene stvaritve na drugih podeželskih odrih, zlasti v Mariboru je bil malone stalen gost. Njegove skladbe so sicer po zgradbi zelo enostavne (pri začetnih delih so očitni vplivi skladateljev singspiela, pa tudi nekaterih italijanskih in francoskih opernih ustvarjalcev prve polovice 19. stol.), kažejo pa na dobro obvladanje kompozicijske tehnike, zlasti izrazito sposobnost vživljanja v različne scenske situacije in razpoloženja. Prim. MGG IX, str. 849-850 (A. Weinmann); Bauer A., Die Musik in den Theaterstücken J. Nestroys, str. 68, 180, 243 do 245; Verzeichnis der Theaterkompositionen von Adolf Müller senior, Ms., Stadtbibliothek Wien, WSB, J. Nr. 67519.

17 Prim. E. H., Das Stadt-Theater in Marburg, Deutscher Bote für Steiermark und Kärnten, Marburg 1898, V., str. 13; Kralj V.ib., IV., str. 15. 
dejavnosti kot pevec nekaj časa (v sezoni 1825/26) gostoval tudi v graškem gledališču. $\mathrm{V}$ razpoložljivem gradivu ni osnove, da bi to lahko zanesljivo trdili.

Razen omenjenih del je Meyerjeva gledališka družba $v$ tej sezoni uprizorila še vrsto manj pomembnih del, ki so jih sicer tedaj večkrat uvrščali v sporede, danes pa so zvečine pozabljena. Od teh je z glasbeno spremljavo uprizorila (januarja 1841) Die Malheure, ${ }^{18}$ lokalno burko Liebreicha z glasbo (?); Hinko der Freiknecht, ${ }^{19}$ igro C. BirchPfeifferjeve z glasbo A. Müllerja sen. in Das Gespenst auf der Bastei, ${ }^{20}$ lokalno komično burko v dveh dejanjih $\mathrm{K}$. Meisla z glasbo F. Volkerta.

V marcu 1841, pred svojih odhodom v Ptuj (kjer je v spomladanski sezoni gostovala), se je igralska družba $C$. Meyerja pomnožila še $\mathrm{s}$ tremi člani: Majettyjem iz Stanovskega gledališča $\mathrm{v}$ Ljubljani in igralko ter igralcem Herzinger iz zagrebškega gledališča. ${ }^{21}$

$\mathrm{Na}$ sporedu so bila predvsem Shakespearova dramska dela (Ukročena trmoglavka), Kleista (Kätchen von Heilbronn) Schillerjeva (Devica Orleanska) ${ }^{22}$ in manj znani igrokazi, izmed katerih tudi naslednji z glasbeno spremljavo: Das Zauberrütchen oder Die Liebhaber als Bettelmusikanten, ${ }^{23}$ čarobno burko v treh dejanjih J. B. Freya z glasbo

18 Prim. Der. Aufmerksame 1841, št. 8 str. 4; skladatelj ni omenjen.

19 Prim. Der Aufmerksame, 1841, št. 8, str. 4; skladatelj v poročilu ni naveden. Hinko der Freiknecht je le del romantične igre Gaugraf Philipp, genannt der Wilde, und Hinko der Freiknecht v petih dejanjih s predigro (Das Testament) - tekst C. Birch-Pfeifferjeve, h kateri je glasbene točke napisal A. Müller sen. 1.1834; prva izvedba 8. III. $1834 \mathrm{v}$ Theatru an der Wien. Prim. Bauer A., 150 Jahre Theater an der Wien, Zürich - Leipzig Wien 1952, 338; Bauer A., Verzeichnis d. Theaterkomp. v. A. Müller sen.

20 Prim. Der Aufmerksame, 1841, št. 8, str. 4.; prva izvedba te burke je bila $\mathrm{v}$ Theatru in der Leopoldstadt 1.X.1819. Skladatelj glasbe $\mathrm{k}$ tej igri, ki v poročilu ni naveden, je Franz Volkert (1778-1845). Sodi sicer med manj pomembne skladatelje komičnega dunajskega singspiela, a poleg W. Müllerja med najplodovitejše, saj je napisal kot kapelnik Theatra in der Leopoldstadt v razdobju od 1810-1829 okrog 150 singspielov, pantomim in burk. Posebno pogosto sta bili izvedeni »Der Kampf mit dem Riesendrachen« in »Der Kampf mit Amazonen«. Prim. Keller O., ib., str. 82; MGG XIII, str. 1920 (K. M. Pisarowitz).

21 Prim. Der Aufmerksame, 1841, št. 41, str. 4.

22 Prim. Der Aufmerksame, 1841, št. 41, str. 4. Glasbena spremljava v poročilu ni navedena. Glasbene točke za Schillerjevo Devico Orleansko je 1.1811 zložil I. v. Seyfried; prva izvedba je bila v Theatru an der Wien 28. X. 1811. Od 1. 1838 dalje so predstavljali Devico Orleansko z glasbo A. Müllerja sen. Prim. Bauer A., 150 Jahre Theater an der Wien, str. 390. Ima pod istim imenom označeno opero, ki jo je napisal F. Volkert (prva izvedba 1.1817 v Theatru in der Leopoldstadt; Prim. Bauer A., Oper und Operette in Wien, str. 52).

23 Prim. Der Aufmerksame, 1841, št. 41, str. 4. V poročilu Das (Die) Zauberrütchen (Wunderrütchen) oder Die Liebhaber als Bettelmusikanten je to delo navedeno kot velika komična čarobna burka s petjem $\mathrm{v}$ treh dejanjih - tekst J. B. Frey; pisec Bauer dodaja, da gre verjetno za predelavo Freyeve čarobne igre Die Wunderrosen (oder Die Brunnenkur des Hexenkönigs). Kot skladatelja omenja A. Müllerja sen. (prva izvedba je bila 2. XII. $1831 \mathrm{v}$ Theatru an der Wien). 
A. Müllerja sen. in Guido von Waldau oder Die Verwechslung, ${ }^{24}$ igra v petih dejanjih J. N. Vogla $z$ glasbo P. J. Riotte.

V sezoni $1841 / 42$ je v mariborskem gledališču spet vodil predstave Carl Meyer s svojim gledališkim ansamblom, $\mathrm{h}$ kateremu so se pridružili tudi novi člani. ${ }^{25}$ Podatki o tej sezoni so znatno skromnejši kot o pretekli (1840/41), vendar je iz njih razvidno, da so na sporedu prevladovale manj pomembne burke in parodije. $\mathrm{O}$ glasbenih prireditvah v gledališču je iz te sezone ohranjen samo en lepak in to o deklamatorično glasbeni akademiji, ki jo je Meyer 29. XII. 1841 pripravil s sodelovanjem solista Petra Singerja ter novega člana družbe igralca in pevca Osinskega. ${ }^{26}$

Zanimanje za gledališke predstave je v sezoni 1841/42 očitno upadlo, kar pripisuje gledališki poročevalec pomanjkanju podpore, ki so je gledališke družbe $\mathrm{v}$ provincialnih krajih znatno $\mathrm{v}$ manjši meri »deležne« kot v večjih mestih. Zato kljub prizadevanju direktorja in članov ne morejo nuditi kvalitetnejšega sporeda, kot bi nekateri zahtevnejši obiskovalci želeli in pričakovali.

če jo presojamo s stališča vrednosti glasbenega in dramskega repertoarja, je bila Meyerjeva enterpriza (če izvzamemo sezono 1841/42) glede na relativno obsežen in kvaliteten sestav uprizorjeñih del najpomembnejša $\mathrm{v}$ prvi polovici 19 . stoletja. V tako majhnem mestu, kot je bil tedaj Maribor, nikakor ne moremo ocenjevati gledališkega repertoarja s takega vidika kot sporede večjih gledališč, npr. ljubljanskega, celovškega ali zagrebškega, kaj šele velikih opernih in dramskih institucij. Poleg tega je bil Maribor zaradi prevelike bližine Gradca v drugačnem položaju kot prej omenjena mesta, ki so kljub tedanjemu značaju province predstavljala večja kulturna središča, v katerih se je gledališko življenje intenzivneje razvijalo kot v Mariboru. Torej moramo imeti pri presoji kulturne dejavnosti in seveda tudi gledališkega repertoarja drugačna merila. Zato izpričujejo uprizoritve Webrove Preciose, W. Müllerjevih operet oziroma singspielov ali Schillerjevih, Kleistovih, Shakespearjevih pa tudi pomembnejših Nestro-

${ }^{24}$ Prim. Der Aufmerksame, 1841, št. 41, str. 4. Skladatelj v poročilu ni omenjen. Napisal pa je glasbene točke $\mathrm{k}$ igri Guido von Waldau ali Die Verwechslung (tekst J.N. Vogla), skladatelj Philipp Jakob Riotte (1776 do 1856), ki je deloval od 1808 na Dunaju - sprva v Theatru am Kärntnertor, od 1818 pa kot dirigent $\mathrm{v}$ Theatru an der Wien. Sodi med manj pomembne, danes že pozabljene skladatelje odrske glasbe v prvi polovici 19. stol. Njegova dela (opere, singspieli, baleti idr.), so skupno z deli $\mathrm{J}$. Seyfrieda in W. Müllerja imela določen pomen $\mathrm{v}$ razvoju dunajske klasične operete. Prim. MGG, XI, str. 346-347 (F. Goebels).

25 Prim. Der Aufmerksame, 1841, št. 156, str. 3 ter 1842, št. 25, str. 4.

26 Prim. MPA, zbirka vabila na prireditve 1790-1939, mapa Maribor gledališče v l.1820-1860. Akademija je imela bolj zabaven značaj in so bile tudi glasbene točke primerno sestavljene. Pri solistu Osinskem pa gre verjetno za istega pevca in igralca - basista Karla Josefa Osinskega, ki je v sezoni 1831/32 nastopal v Ljubljanskem Stanovskem gledališču. Prim. Sivec J., Opera in njena reprodukcija v Stanovskem gledališču v Ljubljani od leta 1790 do 1861, inaug. disertacija, rkp., Ljubljana 1966, str. 259. 
yevih in Raimundovih del resne ambicije in prizadevnost impresarija Carla Meyerja, da z izborom kvalitetnih dramskih in glasbeno scenskih stvaritev iz starejše in sodobne literature vsaj nekoliko dvigne tedanjo raven gledališča nad provincialno povprečje.

\section{SUMMARY}

The theatre company of impresario Carl Meyer hired the Maribor theatre for the 1840/41 and 1841/42 seasons. This Carl Meyer is not to be confused with the famous comedian and theatre director Carl Meyer (1750-1830) who founded the Viennese Theater in der Josefstadt in 1788.

Maribor in those days was a small provincial town which, because of the nearness of Graz, was in a different situation from Ljubljana, Klagenfurt and Zagreb. In spite of a certain provincial character these cities represented bigger cultural centres in which theatrical life could develop more intensively than in Maribor, which did not even have a suitable theatre building. Therefore when discussing the theatrical repertoire of Maribor we have to employ different standards from those applying to more important dramatic and operatic institutions. According to these facts the repertoire of Meyer's company surpassed the programmes of other guest theatre companies in the first half of the 19th century. It was relatively rich and extensive and comprised literarily and musically important works (Weber's Preciosa, W. Müller's operettas and singspiels, Shakespeare, Schiller and Kleist as well as Nestroy's and Raimund's works), which could be found on the programmes of greater contemporary European theatres. 